\title{
COMMUTATORS OF MULTILINEAR CALDERÓN-ZYGMUND OPERATORS WITH KERNELS OF DINI'S TYPE AND APPLICATIONS
}

\author{
PU ZHANG AND JIE SUN
}

Abstract. Let $T$ be a multilinear Calderón-Zygmund operator of type $\omega$ with $\omega(t)$ being nondecreasing and satisfying a kind of Dini's type condition. Let $T_{\Pi \vec{b}}$ be the iterated commutators of $T$ with $B M O$ functions. The weighted strong and weak $L(\log L)$-type endpoint estimates for $T_{\Pi \vec{b}}$ with multiple weights are established. Some boundedness properties on weighted variable exponent Lebesgue spaces are also obtained. As applications, multiple weighted estimates for iterated commutators of bilinear pseudo-differential operators and paraproducts with mild regularity are given.

Mathematics subject classification (2010): 42B20, 42B25, 47G30, 35S05, 46E30.

Keywords and phrases: Multilinear Calderón-Zygmund operator, bilinear pseudo-differential operator, paraproduct, commutator, multiple weight, variable exponent Lebesgue space.

\section{REFERENCES}

[1] R. R. Coifman And Y. Meyer, On commutators of singular integrals and bilinear singular integrals, Trans. Amer. Math. Soc., 212 (1975), 315-331.

[2] R. R. COIFMAN AND Y. MEYeR, Commutateurs d'intégrales singulières et opérateurs multilinéaires, Ann. Inst. Fourier (Grenoble), 28 (1978), no. 3, 177-202.

[3] D. CruZ-Uribe And A. Fiorenza, Variable Lebesgue Spaces: Foundations and Harmonic Analysis, Birkhäuser/Springer, Basel (2013).

[4] D. Cruz-Uribe, A. Fiorenza And C. J. Neugebauer, Weighted norm inequalities for the maximal operator on variable Lebesgue spaces, J. Math. Anal. Appl., 304 (2012), 744-760.

[5] D. CruZ-Uribe And L.-A. WANG, Variable Hardy spaces, Indiana Univ. Math. J., 63 (2014), no.2, 447-493.

[6] D. CruZ-URIBE AND L.-A. WANG, Extrapolation and weighted norm inequalities in the variable Lebesgue spaces, Trans. Amer. Math. Soc., 369 (2017), no. 2, 1205-1235.

[7] L. Diening, P. HaRjulehto, P. HÄStÖ And M. RŮŽIČKA, Lebesgue and Sobolev Spaces with Variable Exponents, Lecture Notes in Math. vol. 2017, Springer, Heidelberg (2011).

[8] X. T. Duong, L. Grafakos And L. Yan, Multilinear operators with non-smooth kernels and commutators of singular integrals, Trans. Amer. Math. Soc., 362 (2010), 2089-2113.

[9] C. FefFerman And E. M. Stein, $H^{p}$ spaces of several variables, Acta Math., 129 (1972), 137-193.

[10] J. García-Cuerva And J. L. Rubio de Francia, Weighted Norm Inequalities and Related Topics, North-Holland Math. Studies, vol. 116, North-Holland Publishing Co., Amsterdam (1985).

[11] L. Grafakos, Modern Fourier Analysis, 3rd ed., Grad. Texts in Math., vol. 250, Springer, New York, 2014.

[12] L. Grafakos, L. Liu, D. Maldonado And D. Yang, Multilinear analysis on metric spaces, Dissertationes Math., 497 (2014), 121 pp.

[13] L. Grafakos And R. H. Torres, Multilinear Calderón-Zygmund theory, Adv. Math., 165 (2002), $124-164$.

[14] L. GRAFAKOS AND R. H. TORRES, Maximal operator and weighted norm inequalities for multilinear singular integrals, Indiana Univ. Math. J., 51 (2002), 1261-1276.

[15] C. Kenig And E. M. Stein, Multilinear estimates and fractional integration, Math. Res. Lett., 6 (1999), no. 1, 1-15. 
[16] A. K. Lerner, S. Ombrosi, C. Pérez, R. H. Torres and R. Trujillo-González, New maximal functions and multiple weights for the multilinear Calderón-Zygmund theory, Adv. Math., 220 (2009), 1222-1264.

[17] K. Li AND W. SUn, Weak and strong type weighted estimates for multilinear Calderón-Zygmund operators, Adv. Math., 254 (2014), 736-771.

[18] Z. LIU AND S. LU, Endpoint estimates for commutators of Calderón-Zygmund type operators, Kodai Math. J., 25 (2002), no. 1, 79-88.

[19] G. Lu AND P. Zhang, Multilinear Calderón-Zygmund operators with kernels of Dini's type and applications, Nonlinear Analysis, 107 (2014), 92-117.

[20] D. Maldonado AND V. NAIBO, Weighted norm inequalities for paraproducts and bilinear pseudodifferential operators with mild regularity, J. Fourier Anal. Appl., 15 (2009), 218-261.

[21] C. PÉREZ, Endpoint estimates for commutators of singular operators, J. Funct. Anal., 128 (1995), $163-185$.

[22] C. Pérez, G. Pradolini, R. H. Torres and R. Trujillo-González, End-point estimates for iterated commutators of multilinear singular integrals, Bull. London Math. Soc., 46 (2014), 26-42.

[23] C. PÉREZ AND R. H. TORRes, Minimal regularity conditions for the end-point estimate of bilinear Calderón-Zygmund operators, Proc. Amer. Math. Soc. Series B, 1 (2014), 1-13.

[24] M. M. Rao And Z. D. Ren, Theory of Orlicz Spaces, Marcel Dekker Inc., New York (1991).

[25] E. M. SteIn, Harmonic Analysis: Real Variable Methods, Orthogonality, and Oscillatory Integrals, Princeton Univ. Press, Princeton, New Jersey (1993).

[26] K. YABUTA, Generalizations of Calderón-Zygmund operators, Studia Math., 82 (1985), no. 1, 17-31.

[27] P. ZHANG AND H. XU, Sharp weighted estimates for commutators of Calderón-Zygmund type operators, Acta Math. Sinica (Chinese Series), 48 (2005), no. 4, 625-636. 